\title{
Antecedent of Organizational Performance
}

\author{
Mashudi Mashudi \\ Magister Manajemen \\ Universitas Muhammadiyah Sidoarjo \\ Sidoarjo, Indonesia \\ emashud_bli@yahoo.co.id
}

\author{
Tiara Nurul Hidayah \\ Magister Manajemen \\ Universitas Muhammadiyah Sidoarjo \\ Sidoarjo, Indonesia \\ tiaranurulh@gmail.com
}

\begin{abstract}
The goal of this study is to conclude and depict the impact of organizational commitment, organizational innovation, and leadership on organizational performance. The approach utilized in this research is quantitative with survey and explanation arrangement. The results of this study state that simultaneously, variable of organizational commitment, organizational innovation and leadership contributes a significant upshot on organizational performance. Organizational innovation and leadership variables are partially influence organizational performance. Leadership variables have the most significant result on organizational performance. The implication for the corporation is that when putting someone in charge, people in charge should able to enhance organizational performance.
\end{abstract}

Keywords-organizational commitment; organizational innovation; leadership; organizational performance

\section{INTRODUCTION}

The discoveries from the preceding research states that organizational commitment, organizational innovation, and leadership has been running well, though there are indications that showed the organizational performance is not maximized. The organizational performance in form of sales level in January to December 2016 is decline in ship sales every moon. These conditions can be made into one indicator that marks decreasing performance of the organization. Hence forth, the problem statement or problem that is that the indicated organizational performance, which has not fulfil the target, can be prepared. The research problem of this research is why the organizational performance has not accomplish the aim. Denoting on to the problem statement and research problem as well, thus research questions can be formulated as follows: 1) Is there simultaneous stimulus of organizational commitment, organizational innovation, and leadership on the organizational performance?; 2) Is there an consequence of organizational commitment, organizational innovation, and partial leadership to organizational performance?; and lastly 3) Which of the variables between organizational commitment, organizational innovation, and leadership that has the most significant impact on organizational performance?

While the aim of this research described as follows: 1) To determine the simultaneous outcome of organizational commitment, organizational innovation, and leadership on the organizational performance; 2) To resolve the influence of organizational commitment, organizational innovation, and leadership partially on organizational performance; and lastly
3) To distinguish which of the organizational commitment organizational innovation, and leadership variables that brings the most significant influences on organizational performance.

The expenditure or benefits of this research are mentioned as follows: 1) For Researchers: to broaden insight and experience on the studied issues both theoretically and practically in the field of human resource management; 2) For the Company: able to give its donation or input to the corporation regarding with the problem that has been researched and then to anticipate the emergence of similar problems further; and 3) For Almamater: as a allusion and references for researchers who brought up the same theme and to add the treasury of research collection of Muhammadiyah Sidoarjo University.[1]

\section{ORgANIZATIONAL COMMITMENT}

Commitment as a state where a certain individual sides an organization along with his/her purposes and wants to maintain his/her membership in the organization [1], commitment in work is perceived as an inclination to provide dynamism, whole-hearted loyalty to the organization and trying to realize the achievement of organizational aims [2]. This commitment is characterized by a strong desire to remain as a member of the organization, the desire to work hard in accordance with organizational desires also with the confidence and acceptance towards organizational values as well as goals so that members of the organization who committed to work are able to realize the accomplishment of organizational goals. Commitment is the key to organizational success. In the interim, organizational commitment is a strong desire to remain as a member of a particular organization, the desire to strive in accordance with the biddings of the organization, as well as certain beliefs and acceptance of organizational values and objectives [1].

An up surging form of commitment is not only in form of passive loyalty, yet it also involves an active relationship with a work organization that has the objective of giving every effort to the attainment of the organization. In other words, organizational commitment is an attitude that reflects employees' loyalty to the organization and the continuous process in which members of the organization express their concern for the organization and its sustained accomplishment and progress.

There are three dimensions of organizational commitment, namely: 1) Affective Commitment, emotional 
sensitivity for the organization and belief on its values. The basic to this commitment is "want to". Individuals with high affective commitment have a strong emotional closeness towards the organization; 2) Normative Commitment, the responsibility to stay with the organization for moral or ethical reasons. The basic of this commitment is the obligation to remain in the organization (ought to). Normative commitment towards the organization can develop from the amount of pressure felt by individuals during the socialization process (from family or culture) and during socialization as new personages entering the organization; and lastly 3) Sustainable Commitment, the assumed economic value of staying in an organization when compared to leaving the organization. The basic of this commitment is the need to survive (need to). Individuals with a high continuance commitment will survive in the organization, not for emotional reasons, but due to the awareness in the individual will be at a huge loss if he/she left the organization to be precise.

Furthermore, three features that affect an employee's commitment, among others as follows: 1) Personal characteristics of workers including their tenure in the organization and variations of different necessity and longings of each employee; 2) Job features, such as the characteristic of the task and the opportunity to interact with co-workers; and lastly 3) Work experience, such as organizational reliability in the past and the way other worker express and convey about their feelings regarding with the organization.

Workers' commitment towards the organization is stratified, from very low levels up to the highest ranks. lowcommitted employees will have an impact on turnover, high attendance, increased work lag and lack of intensity to endure as employees in the organization, poor work performance and lack of loyalty to the company when employee commitment is low then he or she may trigger poor employee behaviour, such as riot actions, which further will decreased organizational reputation, loss of trust from clients and decreased profits as the further impact.

\section{ORGANIZATIONAL COMMITMENT}

Innovation in the broader concept is not actually limited to the product. Innovation can be in a form of ideas, ways or objects perceived by someone as something new. Innovation is also used to refer to perceived alteration as something new people experience. Furthermore, innovation is an economic and social achievement as recognitions to the introduction of new ways of transforming inputs into outputs that create major modifications in the relationship between usage value and the prices offered to consumers and/or users, the community, societies and the environment. [3] mentioned that innovation is the ability to comprehend everything in a new and sometimes out of the ordinary way. provides an organizational concept, which declared that organization mostly understood as a number of specific subject who gathered and cooperated in a structured fashion in quest of attaining the objective or some specific targets predesigned together before [4]. [5]says that organizational performance depends fundamentally on innovation [1].

There are three types of organizational innovation namely product innovation, process innovation, and administration. The underlying argument is that radical and gradual innovation is more specifically appropriated as a characteristic of innovation while product innovation, process and administration are more of a kind of innovation itself. This means that radical and gradual innovation is part of the four innovations mentioned above. Another reason is that radical and gradual innovation describes the intensity and level of organizational transformation, even though both are difficult to measure.

There are four determinant keys of organizational innovation. namely: 1) Vision, a shared idea of a value outcome within an organization; 2) Participatory Safety, which involves many individuals in decision making through mutual influence, interaction, information sharing, support in decision making and development of work procedures. For innovation to transpire, safety is an important element in a participatory environment; 3) Climate for excellence, i.e. real commitment to accomplish superior performance through modification of procedures and implementation of work methods development; and lastly 4) Support for innovation, the open-minded manager always strives to supports innovation[6].

\section{A. Leadership}

According to [7] leadership entails the meaning of influencing others to try more in directing their dynamism, into their duties or to change their behaviour. Leadership broadly involves influencing processes in determining organizational objectives, motivating followers' behaviour to accomplish objectives as well as influence to improve the group along with its culture. It also stimuluses the interpretation of the events of its followers, organizing and activities to accomplish the objectives, maintaining cooperative relations and group work, gaining support and cooperation from people outside groups or organizations[1]. [7] defines leadership as a process of coaxing others to take steps toward a common objective. Leadership is a progression of social influence where leaders seek voluntary participation from subordinates in an attempt to achieve organizational objectives[6].

Leadership has several implications and meanings, among others there are: 1) Leadership means encompassing people or other parties, i.e. employees or subordinates (followers). Employees ought to have the will to receive direction from the leader, however, in the absence of employees or subordinates, leadership will not be overtaken as well; 2) An effective leader is a person with his or her power and able to provoke followers to achieve a satisfactory performance. The power possessed by leaders are sourced from; 3) Reward Power, which grounded on the view of subordinates that leaders have the ability and resources to reward subordinates who follow the direction of their leaders; 4) Corrective Power, grounded on the view of subordinates that leaders have the ability to discipline subordinates who do not follow the direction of 
their leaders; 5) Legitimate Power, grounded on the view of subordinates that the leader has the right to exercise his or her guidance and authority; 6) Referent Power, which is grounded on the subordinates' identification (recognition) towards the leader figure. Leaders can make use of their influence due to their personal characteristics, reputation or charisma; 7) Expert Power, grounded on the subordinates' view that the leader is someone who has competence and have expertise in the specific field. Leaders can practice different forms of control or power to influence subordinate behaviour in various situations; and lastly 8) Leadership must have integrity, compassion, cognizance, courage to act in accordance with belief (commitment), self-assurance in identity and others (confidence) and ability to convince others (communication) in building the organization. Even though leadership is often equated with management, the two concepts are different, but leadership itself is the principal of management.

\section{B. Organizational Performance}

Performance is a depiction of the level of implementation accomplishment of an activity or policy program in realizing the goals, objectives, vision and mission of the organization transferred through strategic planning of an organization. Performance can be known and measured if an individual or group of employees has the criteria or standard of accomplishment of the benchmarks established in the measurement, then the performance on a person or the performance of the organization is implausible to be known if there is no benchmark for its accomplishment [7]. [1] states that performance can be defined as the result of work in quality and quantity that can be achieved by an employee in performing errands in accordance with the responsibilities given to him. The organization is any form of partnership between two or more persons who works together and are formally bounds in order to achieve a predetermined objective.

From the definition of performance above, we can concluded that the level ofthe implementation achievement of tasks performed by all employees who exist in an organization/company is the goal that must be attained by the organization in exploiting the responsibility earned. While the definition of the organization form explanation above, it can be concluded that an organization can be formed due to its influence by several aspects such as the unification of vision, mission, and the same objective with the realization of the existence of a group of people to the community.

An organization is deliberated as good if the organization is recognized by the surrounding community, due to its contributions such as the empowerment of human resources from the surrounding community as its members; it can suppress the unemployment rate. From several of the above performance and organizational definitions, can inferred that the performance and organization is a stand-alone variable. However, when the performance and organization are combined, it will produce a new variable named the performance of the organization that covers many things.

There are three types of performance known that can be distinguished in an organization, which described as follows: 1) Operational Performance: This performance is related to the utilization effectiveness of each resource used by the corporation; 2) Administrative Performance: This performance is related with the performance of the organization administration, including the administrative structure governing the connection of the authority and responsibility of the person holding the position; and 3) Strategic Performance: This performance is associated to the corporation performance, evaluated the corporation accuracy in choosing the environment and the corporation adaptability, especially in the company's strategy in carrying out its vision and mission.

performance indicators are often associated with performance measures, though both are actuallyin the same criteria of performance measurement, but there are different senses and meanings [7]. Generally, the performance indicator gauge can be assembled into the following four categories: 1) Effectivity, this indicator measures the degree of conformity of the produced output in attaining something desired; 2) Efficiency, this indicator measures the degree of conformity of the process to output creation using the lowest possible cost; 3) Quality, this indicator measures the degree of conformity between the quality of the product or service formed with the necessities; 4) Timeliness, this indicator measures whether the work has been finishedpunctually and on time [1].

A research result mentioned that the most influential independent variables are job satisfaction with coefficient of 0.456 . Then followed by organizational culture variable with coefficient of 0,021 . Variabel which have the lowest effect is organizational commitment variable with coefficient of 0,073 . While the organizational commitment variable is negative [9]. This means that with increasing discernments of respondents about organizational commitment, then resulted in the lessening performance of public organizations.

Another research result identified that: 1) organizational commitment partakes a significant positive influence on the public organizations performance; 2) organizational culture has a significant positive impact on the public organization performance; and lastly 3) job satisfaction has a significant positive result on the public organization performance.

Research entitled "Organizational Innovation Pattern, People Equity, and SME Performance". The outcomes of his research can be identified that in general, the performance of SMEs (KE) is at a score of 5.19. This indicates that respondents feel SMEs have a rather high performance. The substances that get the highest response are the ability to innovate (KE1) that is equal to 5.37. This illustrates that the respondent senses that his or her organization workplace has a high tolerance for innovation. Moreover, this shows that organizational innovation has a significant positive effect on SME performance [1].

\section{METHOD}

This research was designed by utilizing a quantitative approach, as well as using the format of explanation and survey. Data collection done by employing questionnaires distributed to respondents who simultaneously act as the sample of 50 employees. Samples were taken by random sampling from total population of 102 employees. The data is 
processed by multiple linear regression analysis technique with the help of SPSS program version 17 for Windows.

\section{FINDING AND DISCUSSION}

The validity test results indicated that all the questions in the valid questionnaire and reliability test results identified that all variables are reliable. From the classical assumption, test results obtained information that is: 1) all variables linearly bound with independent variables; 2) distribution of normal data; 3) no mulcolinearity problem; 4) no heteroscedasticity problem; and 5) there is no autocorrelation problem. By observing, the results of classical assumption test can be inferred that the data can be further processed by multiple linear regression analysis techniques.

From the outcomes of $\mathrm{F}$ test or simultaneous test, independent variables consisting of organizational commitment, organizational innovation, and leadership instantaneously have a significant effect on organizational performance, with a significance value of 0.000 (below 0.05 ) and $F$ value counted 20,788 (above F table of 2,370). From the outcome of $\mathrm{T}$ test or partial test, two variables that consist of organizational innovation and leadership partially have significant influence to organizational performance, with significance value equal to 0,005; and 0.002 (less than 0.05). While the organizational commitment variable is not significant, with a significance value of 0.104 (greater than 0.05). Obtained information settled that leadership variables have the most significant effect on organizational performance variable compared to other independent variables. Aside from that, obtained information also mentioned that $\mathrm{R}$ Square is 0.576 . Thus, it can be quantified that the independent variables contribute in forming the dependent variable of $57.60 \%$. This means that there are still $42.40 \%$ other independent variables that are not involved in this research.

Leadership variables significantly influence the performance of the organization with a significance value of 0.002. Accordingly, the higher the value of decision-making aptitude, motivating ability, communication skills, capability to control subordinates, responsibility, as well as emotional control capacity, the higher the performance of the organization will be. The results of this study are relevant to the results of research conducted by Abdul Hakim, in 2006, which defines that leadership has a significant effect on company performance [8].

Variables of organizational innovation significantly influence the performance of the organization with a significance value of 0.005 . Henceforth, the higher the value of service line extensions, service improvements, and style changes, the higher the performance of the organization. The outcomes of this study support the research findings, which explained that organizational innovation that includes technological innovation, innovation, and strategic innovation contributes a significant positive effect on organizational performance [9]. The results of this study are also relevant compared to the results of research which states that organizational innovation has a significant positive impact on the performance of SMEs[5].

The next variable is organizational commitment. Organizational commitment variable has an effect on organizational performance though its influence is not as significant as other, with significance value equal to 0,104 (greater than 0,05). Thus, although there is an increase in the value of affective commitment, normative commitment, and continuance commitment, the increase in value has no significant effect on the increase of organizational performance.

\section{CONCLUSION}

The test result of simultaneous influence of independent variable towards dependent variable can be inferred that the variable of organizational commitment, organizational innovation, and leadership concurrently have significant influence to organizational performance. Partial test results of the influence of independent variables towards the dependent variable can be concluded that the variable of organizational innovation, and leadership partially have a significant influence on organizational performance. Organizational commitment variable influences organizational performance, though its influence is not as significant as others are. The result of determinant coefficient test ( $R$ Square) shows that $57,60 \%$ organizational performance is influenced by organizational commitment, organizational innovation and leadership, while $42,40 \%$ of organizational performance is influenced by other variables outside of variable in this research.

\section{ACKNOWLEDGMENT}

The researchers would like to thank to Universitas Muhammadiyah Sidoarjo.

\section{REFERENCES}

[1] F. Luthans, "Organization Behaviour, (Translator: V.A Yuwono, et al),Bahasa Indonesia Edition," Yogyakarta: ANDI., 2006.

[2] LaksonoTrisnantoro, "Strategic Aspectin Hospital Management, First Print," Yogyakarta Andi Publ., 2005.

[3] Y. M. Anshori, "The Impact of Market Orientation, Intellectual Capital and Learning Orientation towards Innovation," vol. 3, pp. 317-329, 2011.

[4] M. Mahsun, Measurement of Public Sector Performance. Yogyakarta: BPFE, 2006.

[5] Muafi, "Pattern of Organization Connection, People Equity and SME Performance. Journal of UPN Yogyakarta."

[6] R. Kreitner, Organizational Behaviour. 2005.

[7] Moeheriono., Competency Based Performance Measurement. jakarta: Rajawali Pers, 2012. 
[8] A. Hakim, "The Influence Analysis of Leadership, Organizational Commitment, and Organizational Climate towards the Performance of Office of Transportation and Telecommunication Administration of Middle Java Province.," no. 2, pp. 165-180, 2006.

[9] A. Gusti Ruzayda Eka Hapsari, Djumilah Hadiwidjojo, "The Effect of Organizational Learning, Market Orientation and Organizational Innovation towards Competitive Advantages (Study on Bank Rakyat Indonesia Inc. if Malang Raya Branch).," Manag. Appl. J., vol. 12, 2014. 